\title{
Interview with Charles M. Reigeluth: Applying Instructional Design to Educational Reform
}

\author{
Ali Simsek \\ Anadolu University, Turkey
}

Charles M. Reigeluth is one of the most contributing and certainly the leading scholars in the field of educational technology and instructional design. His early contributions were about developing instructional design theories such as Elaboration Theory and Component Display Theory. He has also edited monumental books as collections of major ID theories and models. His recent work has focused on designing educational reform or transforming educational systems with a comprehensive instructional design perspective, which he calls it "informationage paradigm of education."

Professor Reigeluth has received many awards for his accomplishments and contributions in the field of educational technology and instructional design. Most of these awards were given by prestigious organizations and educational institutions such as Brigham Young University, AECT, AERA, ISPI, and Indiana University. However, probably his biggest award is witnessing that his ideas have been implemented by a number of school districts in the United Sates and influenced many others around the world. Considering his accomplishments and contributions that shaped our field over the years, we decided to interview him and he was generous enough to share his views with us.

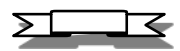

\section{When and where did you start your academic career?}

I became interested in educational reform when I was 16 years old, due to frustration with the courses I was forced to endure. Since Harvard was a liberal arts college, there was no major in education, and I loved the introductory course in economics, so I decided to major in it. Then, when I graduated, I figured out that I needed to teach for several years to have any credibility to educators, so I taught high school science. My first job as a professor was at Syracuse University, in the Instructional Design, Development \& Evaluation program, starting in August 1978. It was right after a 1-year post-doc experience at Brigham Young University.

Who were the famous figures in the field and what were they studying then?

In my area of interest, instructional theory, Bob Gagné was probably \#1, followed by Jerome Bruner, B. F. Skinner, David Ausubel, and Dave Merrill. All but Merrill were at, or close to, the end of their careers. Gagné's major work was based on information-processing theory and included the nine events of instruction and hierarchical sequencing of instruction. Also, he was soon to author a book with Bob Reiser applying those ideas to media selection. Bruner's work was based on cognitive theory and included the spiral curriculum and enactive, iconic, and 
symbolic modes of representation, among other things. At the time (1978) he was in the middle of several decades of work using these and other ideas to develop a complete curriculum for pre-collegiate education called Man: A Course of Study. Skinner's work was based on behaviorism and included such things as reinforcement, shaping, and teaching machines. I don't think he was still making important contributions at the time I began my career as a professor. Ausubel's work was based on cognitive theory and included advance organizers and instructional sequences to promote subsumption of new ideas within cognitive structures. He was working on a book with Novak and Hanesian at that time. Finally, Dave Merrill, who was my mentor for my doctoral studies at Brigham Young University, as working on Component Display Theory and the Instructional Strategies Diagnostic Profile, both of which addressed instruction for teaching individual knowledge, skills, and understandings. Also, we began to develop the Elaboration Theory at that time.

\section{Which subject did you work on for your doctoral dissertation?}

I conducted a research study on the effects of generalities, examples, and practice (with feedback) for teaching a skill. It found that practice had the largest effect on learning, though that effect was reduced (but still significant) when examples were provided. Generalities had the least impact on learning. This study supported Merrill's Component Display Theory and the notion of learning by doing.

\section{Who was your advisor and what did you learn from him/her?}

Dave Merrill was my primary advisor at Brigham Young University. I learned how to be an instructional theorist and researcher from him. I also learned a lot about instructional theory from him. And I learn how to be a caring and supportive professor. I owe him much and have great affection for him.

\section{Have you been involved in important projects during your graduate years?}

Vic Bunderson got me involved in the TICCIT system, a computer-based instruction system based on Merrill's Component Display theory. I conducted my dissertation on this system. Dave Merrill got me involved in a project to develop the Instructional Strategy Diagnostic Profile for the Navy Personnel Research \& Development Center. This led to a book chapter titled "The Instructional Quality Profile."

\section{How did your work on Elaboration Theory begin?}

It began in a conversation with Dave Merrill about the need to advance instructional theory on the macro level, to complement Component Display Theory's contributions on the micro level. It was driven by a desire to have a holistic alternative to the piecemeal approach offered by Gagné's hierarchical sequence. I almost did my dissertation on Elaboration Theory but opted for a more manageable experimental study. My initial conception of ET was as a pyramid of knowledge, where instruction could begin with a horizontal slice across the top of the pyramid and one could delve into progressively deeper slices of parts of the pyramid that interested them. In discussions with Dave Merrill, I switched to the zoom lens analogy, which I have described in several of my publications. Operationalizing it was the major challenge. The first breakthrough came with an understanding of Ausubel's work. Bruner's spiral curriculum led to another breakthrough. Scandura's path analysis was the third. Those three corresponded to Merrill's distinction between concepts, principles, and procedures. So I was able to offer 
specific guidelines for a zoom lens approach for each of those three kinds of skills: general to detailed, fundamental to elaborate, and simple to complex.

\section{What was your contribution to Component Display Theory?}

I did not really play a role in its development while at BYU. I did play an important role in using it to develop the Instructional Strategy Diagnostic Profile and the Instructional Quality Profile. Also, while at Syracuse University, I extended the Component Display Theory in a set of modules for a course of mine on instructional theory. I created one module each for invariant tasks (memorization), concept classification, principle using, procedure using, understanding, generic (higher-order thinking) skills, and attitudes. All these materials are available at http://www.indiana.edu/ idtheory/methods/methods.html.

\section{What did your work on Simulation Theory produce?}

The article I co-authored with Ellen Schwartz was the only publication directly on simulation theory, though much of that theory has been incorporated into my recent work on an instructional theory for the information-age paradigm of education and my design theory for a Personalized Integrated Educational System (PIES). Both are described in an article available at http://www.um.es/ead/red/32/.

\section{How did you become involved in the work on Educational Reform?}

Educational reform has been an interest of mine since I was 16 years old, due to my own frustrating experiences as a high-school student. In 1974, I believed that computers were going to be an important part of what was needed to make learning more enjoyable and meaningful, which led me to BYU because of the TICCIT system. There, I soon learned that instruction could be as bad on a computer as in a classroom, so I realized that instructional theory needed to be further developed before the kind of educational system I envision would be possible. After working on instructional theory for about a decade, I felt that knowledge was developed to the point where I should begin to work on educational reform, or more accurately, educational transformation. My first publication in this area (1983) was about what an educational system should be like. Soon I realized that such a dramatic transformation would be very difficult to bring about, so I turned to advancing knowledge about how to help a school system to transform itself. Fortunately, Indiana University gave me the opportunity to teach courses and conduct field-based research in this area, even though it was previously unknown in programs on instructional systems design.

\section{Is it possible to design an educational reform like an educational technology?}

If you are starting a school system from scratch, there are many parallels to designing an educational technology. You need a theory of education (broader than a theory of instruction) to guide the design, and you will need careful selection and extensive training of staff, because few people will have had experience with the new roles required in the learner-centered paradigm of education. So both the design and implementation processes are more extensive. However, if you are transforming an existing system, you have a much more complex process because the learner-centered paradigm requires a different mindset about education. The larger the system, the more complex and time-consuming the process will be. I recommend involving all stakeholders in creating a vision for their new system, because this will be a learning process that will help them to evolve their mindsets, and their sense of ownership of 
the changes will greatly reduce resistance to the transformation. The user-design process must be a consensus-building process rather than a more traditional decision-making process. However, this is time-consuming, and educators and parents alike are very short on time, so funding is needed in the summer to buy people's time to engage in this design process, or it process will take years.

\section{Have your reform ideas been implemented by any school?}

Yes, there are many schools, mostly charter schools that have implemented some early versions of the information-age, learner-centered paradigm. They include 37 Edvisions schools (including the Minnesota New Country School), 3 schools in the Chugach School District, hundreds of Montessori schools, the Free School in Brooklyn NY, the Great Expectations Charter School, Highland Tech Charter School, and to a slightly lesser extent 42 Big Picture Learning Schools, 2 Carpe Diem Schools, 2 Ingenium Schools, 9 schools in the Kuspuk School District, 19 schools in the Adams 50 School District, 11 schools in the Lower Yukon School District, and many more. We are conducting an extensive survey project to identify such schools throughout the United States. Our criteria for selecting the schools are: attainmentbased student progress, personalized learning, collaborative project-based learning, criterionreferenced student assessment, and multi-age grouping with multi-year mentoring.

\section{Can you tell us about your monumental work on ID theories and models?}

When I began my career as a professor, most of the attention in the field of instructional systems design was on the ISD process; very little attention was paid to instructional theory (guidance for what the instruction itself should be like). My goal with Volume 1 of the "Green Book" was to focus more attention on instructional theory. As my understanding of the information-age paradigm of education deepened, I felt there was a need to describe work on learner-centered instructional theories and all aspects of human development, so that was the goal of Volume 2. More recently, I recognized the need to develop a common knowledge base in instructional theory, because so much energy was spent in "reinventing the wheel" with many new instructional theories. I also felt it was more important to advance knowledge about "situationalities" - those particular aspects of situations that call for differences in instruction. So those were the goals of Volume 3.

\section{What are the awards have you received and how do you feel about them?}

I don't put much stock in awards, because I have found they tend to be mostly political. I have received the Honored Alumni Award from BYU's School of Education, the Distinguished Service Award from AECT, 11 awards for outstanding book and outstanding journal article from AECT, AERA, and ISPI, Teaching Excellence Recognition Award from Indiana University, and several others.

\section{Which universities have you worked for so far?}

I have worked at Brigham Young University (Ph.D. program and 1-year post-doc), Syracuse University (10 years up to full professor and chair of the Instructional Design, Development \& Evaluation program), and Indiana University (almost 25 years, including several years as department chair). 


\section{Which countries have you worked in and what did you do there?}

I ran a 2,500-acre farm in Argentina for 3 years. I have given presentations on paradigm change and instructional theory in Spain, Mexico, Canada, South Korea, Taiwan, China, Japan, and Turkey.

\section{How many doctoral theses have you supervised?}

I don't know how many I supervised at Syracuse, but 45 have been completed so far at Indiana University. Most were about instructional theory and the paradigm change process in public school systems.

\section{What is your most important accomplishment?}

It is yet to come. I am about to publish a book on paradigm change in education that I think will be my most important contribution to date. And hopefully that will lead to opportunities to help school systems around the world to transform to the information-age paradigm. The book addresses what paradigm change is, why it is so desperately needed to improve educational systems, a vision of the information-age paradigm, three examples of current school systems that fit the vision, guidance for transforming to the new paradigm, and things that governments can do to support paradigm change.

\section{Is there anybody in the academia that you admire?}

I admire academics who help change the world for the better. Robert Reich has provided great insights about how the world of work is changing, with important implications for transforming educational systems. Alvin Toffler's insights about the three great waves of change and how they impact all sectors of society are truly profound, with uncannily accurate predictions. In education, Jerome Bruner developed Man: A Course of Study, which includes brilliant advances in curriculum and instruction.

\section{How do you see the future of educational technology field?}

The future lies in the new paradigm. We need to develop much additional knowledge about instructional methods (instructional theory) and ways technology can be used most effectively to support the whole system. Regarding instructional methods, I foresee project-based learning being the foundation, but with an instructional overlay that overcomes the shortcomings of PBL to ensure mastery, transfer, automatization (when appropriate), and efficiency of learning. Regarding technology, there are four major functions that technology must serve: keeping records about what every student knows (an inventory of attainments), planning what each student should learn next (a personal learning plan), providing an authentic PBL environment with instructional overlay (instruction), and assessing individual students' mastery of all the standards addressed by each project (assessment). These functions should all be seamlessly integrated. For more information about both the instructional theory and the technology, please see my recent article at http://www.um.es/ead/red/32/.

\section{What would you like to recommend to young colleagues?}

We desperately need people to advance knowledge about the new paradigm of education in the two areas just mentioned: PBL with instructional overlay, and an integrated technology 
system that provides the recordkeeping, planning, instruction, and assessment functions. We also need much more knowledge about how to help existing school systems to transform themselves to the new paradigm.

It is important for scholars to be open-minded, constantly skeptical about their own ideas, curious about others' ideas and research, able to view the world through multiple perspectives (philosophies, theories, etc.), and persistent in getting their work published. Also, understand that, of all the major contributions to the field, the vast majority are design theories, not research studies. Consider focusing all your work (including research studies) on advancing design theories. Also, conduct your research studies within the framework of a design theory, with the purpose of improving it.

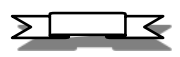

Charles M. Reigeluth's contributions have certainly been enlightening for many researchers in the field of educational technology and instructional design. In addition to his own associates, many graduate students around the world have studied the theories and models he has developed. The most prominent examples include Elaboration Theory, Component Display Theory, Information Age Paradigm, Personalized Integrated Educational System, Project-Based Learning, and Educational Reform as Transformation of School Systems.

Professor Reigeluth emphasizes that the work of educational technology researchers should focus on advancing instructional design theories rather than investigating some trendy aspects of utilizing educational media in schools. He makes the point that such an orientation will provide a comprehensive framework for efforts toward improving education dramatically in the knowledge-driven societies of the twenty-first century. This is to say that nobody can transform schools without providing personally meaningful experiences for all learners in an integrated system of education.

Correspondence: Ali Simsek, Professor, Institute of Communication Sciences, Anadolu University, Yunus Emre Campus, Eskisehir, Turkey 